\title{
Segurança de obras raras como possível objeto de estudo da Ciência da Informação
}

\author{
Security of rare books as a possible object \\ of study in Information Science
}

Raphael Diego GREENHALGH'1

Miriam Paula MANINI'

\section{Resumo}

Não há um consenso sobre os limites de atuação da Ciência da Informação, como também não há uma definição assertiva para o próprio conceito de informação. Por meio da análise de algumas definições de Ciência da Informação e de conceitos de informação na literatura da área, este trabalho busca justificar a segurança contra roubo ou furto de Obras Raras como possível objeto de estudo da Ciência da Informação. São abordadas as características do livro raro como documento dotado de memória individual e coletiva, transcendendo a ideia do livro como mero suporte de informação, percebendo-o como objeto informacional. Essa percepção se dá a partir das ideias de Buckland, juntamente com os paradigmas descritos por Capurro, que, principalmente com relação ao paradigma físico, mostra a Ciência da Informação preocupada com as necessidades de informação focadas no documento, ou seja, com a informação emitida por meio de objetos com valor informacional.

Palavras-chave: Biblioteconomia. Ciência da informação. Obras raras. Segurança contra roubo.

\begin{abstract}
There is no consensus about the limits of Information Science as there is not only one definition for the concept of information itself. The aim Information Science by analyzing definitions and concepts of information available in the literature. It also addresses the characteristics of Rare Books as documents with/containing individual and collective memory, transcending the idea that the book is simply a carrier of information, but rather an informational object. This perception borrows ideas from Buckland, along with the paradigms described by Capurro which, regarding the physical paradigm, shows Information Science concerned with the information needs focused on the document, i.e., with the information provided by objects with informational value.
\end{abstract}

Keywords: Librarianship. Information science. Rarebook. Security against theft.

\section{Introdução}

A Ciência da Informação (Cl) surgiu dos problemas científicos presentes na recuperação da informação; entretanto, as ambiguidades do termo informação impedem que seja delimitado de forma assertiva o escopo de atuação da $\mathrm{Cl}$.

\footnotetext{
1 Universidade de Brasília, Faculdade de Ciência da Informação, Programa de Pós-Graduação em Ciência da Informação. Campus Universitário Darcy Ribeiro, Asa Norte, 70910-900, Brasília, DF, Brasil. Correspondência para/Correspondence to: M.P. MANINI. E-mail: <mpmanini@uol.com.br>

Recebido em 25/10/2012, reapresentado em 13/5/2013 e aceito para publicação em 21/5/2013.
} 
cultural e, em alguns casos, pela escassez de seus exemplares (desde que essas condições atribuam singularidade aos exemplares). Portanto, o livro raro transcende a noção do livro como suporte de informação, tornando-se objeto informacional e se aproximando da noção de informação-como-coisa empregada por Buckland (1991).

O objetivo deste trabalho é demonstrar como a segurança contra roubo e furto de Obras Raras pode ser analisada a partir de conceitos da Cl. Foram verificadas as definições da própria $\mathrm{Cl}$ e do seu objeto de estudo - a informação -, para entender, dentro das definições de livro raro, em que categoria informacional este se enquadra.

\section{Definições de Ciência da Informação}

Conforme Wersig e Neveling (1975), a dificuldade em se analisar os fenômenos pertencentes à Cl ocorre pela diferença na formação dos "cientistas da informação", oriundos de áreas como Biblioteconomia, Ciência da Computação, Filosofia e Linguística, entre outras; pela inexistência de estudos sobre sua derivação histórica; e pelas diferenças terminológicas do termo informação. Observa-se que, em sua origem, a preocupação inicial da Cl estava principalmente na recuperação da informação. Para Saracevic (1996), a recuperação da informação foi a grande responsável pelo desenvolvimento da Cl, apesar de não ter sido a única. Esta ideia está presente nas definições de $\mathrm{Cl}$ apresentadas por Robert Taylor e sintetizadas por Borko na seguinte definição:

Ciência da Informação é a disciplina que investiga as propriedades e o comportamento da informação, as forças que regem o fluxo de informações, e os meios de processamento de informação para melhor acessibilidade e usabilidade. Preocupa-se com o corpo de conhecimentos relacionados com a origem, coleta, organização, armazenagem, recuperação, interpretação, transmissão, transformação e utilização da informação. Isto inclui a investigação de representações de informação em ambos os sistemas naturais e artificiais, o uso de códigos para transmissão eficiente de mensagens, bem como o estudo dos dispositivos de processamento de informação e técnicas, tais como computadores e sistemas de programação (Borko, 1968, p.1, tradução nossa) $)^{3}$.

Na origem, os estudos desenvolvidos pela Cl preocupavam-se com a necessidade de informação com foco no documento, em como este seria recuperado mediante a representação que se faria de seu conteúdo e de suas características. Esta abordagem seria posteriormente chamada por Capurro (2003) de paradigma físico da $\mathrm{Cl}$, no qual a informação seria emitida por meio de objetos com valor informacional, como, por exemplo, os livros.

Para o Capurro (2003) atualmente ainda existem outros dois paradigmas dentro da Cl que evoluíram a partir do paradigma físico. Um deles é o paradigma cognitivo, onde o conhecimento presente nos documentos - ou objetos físicos-, tem a capacidade ou não de transformar o estado de conhecimento do usuário.

Esta ciência é baseada na noção das necessidades de informação de certas pessoas envolvidas em trabalho social, e relacionadas com o estudo de métodos de organização dos processos de comunicação numa forma que atenda a estas necessidades de informação. O termo básico "informação" pode ser entendido somente se definido em relação a estas necessidades de informação. Quer como redução da incerteza causada por danos comunicados. Ou como dados usados para reduzir incerteza (Wersig; Neveling, 1975, p.138, tradução nossa) ${ }^{4}$.

O outro é o paradigma social, descrito por Capurro (2003): o usuário não é mais visto de forma isolada, mas como um ser que interage com o meio, e suas necessidades de informação são influenciadas por suas relações sociais.

Para Capurro (2003), os três paradigmas não se excluem, ou seja, a Cl ainda se dedica a entender e a

\footnotetext{
3 "Information Science is that discipline that investigates the properties and behavior of information, the forces governing the flow of information, and the means of processing information for optimum accessibility and usability. It is concerned with that body of knowledge relating to the origination, collection, organization, storage, retrieval, interpretation, transmission, transformation, and utilization of information. This includes the investigation of information representations in both natural and artificial systems, the use of codes for efficient message transmission, and the study ofinformation processing devices and techniques such as computers and their programming systems".

4 "This is science is based on the notion of the information needs of certain people involved in sociallabour, and of concern with the study of methods of organization of communication processes in a way which meets these information needs. The basic term 'information' can be understood only if it is defined in relation to these information needs. Either as reduction of uncertainty caused by communicated data. Or as data used for reducing uncertainty".
} 
elucidar os problemas apresentados pelos paradigmas físico, cognitivo e social.

\section{O que é informação para a Ciência da Informação?}

Um dos problemas em se definir e/ou delimitar a Cl está na dificuldade de apontar o seu objeto de estudo: a informação. Para Wersig e Neveling (1975), existem seis abordagens para o uso e significado de informação:

1) Abordagem estrutural (orientada para a matéria): as estruturas do mundo - quer possam ser apreendidas ou não -, constituem "informação".

2) Abordagem do conhecimento: o conhecimento elaborado à base da percepção das estruturas do mundo é "informação"; depende da apreensão da informação pelo indivíduo.

3) Abordagem da mensagem: "informação" é frequentemente usada como sinônimo de "mensagem" (ou seja, refere-se a como o conteúdo da informação é medido pela mensagem).

4) Abordagem do significado (característica da abordagem orientada para a mensagem): aceita somente o significado da mensagem como "informação".

5) Abordagem do efeito (orientada para o receptor): a"informação"somente ocorre como um efeito específico de um processo específico ou não específico.

6) Abordagem do processo: "informação" não é um dos componentes do processo, mas o próprio processo.

Essas abordagens estão presentes nos paradigmas da Cl propostos por Capurro (2003), principalmente nos paradigmas físico e cognitivo. No primeiro, a informação está nos objetos físicos e, no segundo, a apreensão da informação depende das necessidades de informação dos indivíduos, mudando ou não seu estado de conhecimento. Contudo, nessas abordagens não se vê muitos elementos que os integram ao paradigma social, pois não está presente a preocupação de entender o usuário dentro de um contexto social capaz de influenciar suas necessidades de informação, em parte porque esta visão foi consolidada após a publicação do artigo de Wersig e Neveling (1975).
Buckland (1991) trabalha com três conceitos de informação, que convergem com as abordagens descritas anteriormente:

1) Informação-como-processo: informação entendida como o ato de informar, de comunicar o conhecimento transformando o receptor.

2) Informação-como-conhecimento: o conhecimento é usado para minimizar as incertezas.

3) Informação-como-coisa: a informação está presente no conhecimento comunicado, ou seja, nos objetos, nos documentos.

As perspectivas apresentadas sobre o conceito de informação mostram sua ambiguidade e tentam defini-lo com termos tão ambíguos quanto a própria informação, como no caso do uso do "conhecimento, mensagem e significado" como sinônimos de informação.

Diante dessas múltiplas e incertas definições e usos do termo informação, Capurro e Hjørland (2007) decidem fazer uma regressão às origens do termo, a fim de encontrar algo que possa defini-lo com maior exatidão. Chegam à conclusão de que não é possível, por meio do levantamento histórico, chegar a um conceito unívoco, mostrando que o termo não dever ser visto isoladamente, mas em comparação com outros termos, como documento e mídia. Eles também são contra o uso assertivo do termo informação e dizem que a sua distinção mais importante está entre informação-como-coisa ou como signo, passível de interpretação de um agente cognitivo.

\section{Definição de obras raras}

Uma das situações de atribuição de raridade ao livro está ligada à escassez de seus exemplares, que pode ter ocorrido de forma intencional ou casual, pois podem ter sido produzidos poucos números daquele título, ou mesmo ter sido censurado, ou, ainda, repudiados pelo autor. Contudo, esta não é a única condição que traz raridade a um título, pois também são considerados raros os livros que têm relevância histórica e cultural, sendo levados em consideração aspectos relacionados à sua importância para uma área do conhecimento, para um povo ou nação, para a humanidade como um todo e até mesmo para a própria área que trata sobre a"História do Livro". Cada livro também é um objeto particular com 
sua própria história, ou seja, os exemplares de uma mesma edição podem se diferenciar entre si dependendo das mãos pelas quais passaram, ganhando também características extrínsecas à sua produção, como uma assinatura, anotações, o Ex libris de alguma personalidade, ou mesmo uma encadernação diferenciada pelo material usado na confecção, que também podem lhe conferir raridade.

Os manuscritos produzidos antes da invenção da imprensa por Gutenberg (aproximadamente 1450) são considerados Obras Raras de forma unânime, pois o próprio método de fabricação do pergaminho e a forma artesanal da escrita e das ilustrações (iluminuras) foram determinantes para que poucos exemplares de um mesmo título fossem produzidos e para que fossem frequentemente diferentes entre si, visto que as cópias não eram feitas por uma única pessoa, o que resultava em diferentes composições estilísticas tanto na escrita quanto na arte ilustrativa, dando um caráter de unicidade a cada livro.

Quanto ao livro impresso, uma categoria de inegável raridade é a dos chamados incunábulos, que correspondem aos primeiros impressos até o ano de 1500, pois os mesmos trazem características de produção vindas dos manuscritos, como a adoção de duas colunas textuais, ausência de folha de rosto e abreviação de texto.

As obras impressas até o final do século XVIII são geralmente consideradas raras indistintamente pelas bibliotecas, pois houve uma expansão do mercado livreiro no século XIX, fazendo com que as obras tivessem uma tiragem mais ampla para satisfazer à demanda, o que torna raros os livros anteriores a este período por causa da fabricação de forma artesanal, como aponta Sant'Ana (2001, p.5), ao mostrar que "Durante quase 350 anos, no período que vai de Gutenberg até o final do século XVIII, todos os livros foram produzidos praticamente do mesmo modo". No Brasil, essa data não é considerada isoladamente, pois a imprensa só vai chegar definitivamente em território brasileiro com a vinda da Família Real, em 1808, e a consequente criação da Imprensa Régia, como mostra Rodrigues (2006).

A data relacionada à produção livreira no Brasil adotada pelas bibliotecas como critério de seleção é muito variada. A Biblioteca Nacional ([2000]), por exemplo, considera como raros todos os livros publicados aqui no Brasil até o ano de 1841; mas a Biblioteca do Centro de
Filosofia e Ciências Humanas da Universidade Federal do Rio de Janeiro leva em consideração o ano de 1900 (Universidade Federal do Rio de Janeiro, [2012]). A Biblioteca Central da Universidade de Caxias do Sul adota até 1860, como apontado por Rodrigues (2006). A Biblioteca Ministro Oscar Saraiva, do Ministério da Justiça, considera como Obras Raras todos os livros publicados até 1910, não só no Brasil, mas também no exterior, como mostram Menezes e Silva (2004).

Moraes (2005) mostra que os livros que tratam sobre o Brasil, seja em sua íntegra ou mesmo de forma superficial, passaram a ser mais procurados pelos colecionadores, devido à preocupação com o resgate dos documentos que armazenam a história do País, nomeando, assim, a totalidade dessas obras até o ano de 1900 como Brasiliana. A partir dessa procura, este passaria a ser um critério de seleção de Obras Raras adotado em várias bibliotecas brasileiras, como no caso da Universidade de Brasília.

O valor cultural nem sempre está ligado à data de publicação, pois vários autores recentes se consagraram por suas ideias e modificaram as áreas do saber. Vários são os critérios adotados para tentar identificar essas obras relevantes para a sociedade, independentemente do período em que foram produzidas.

Reifschneider (2008) descreve outros critérios de seleção que tentam captar essas obras que possuem alto valor cultural; um deles leva em consideração a censura empregada a determinadas obras, pois algumas tiveram quase todos os seus exemplares queimados por censores, como aconteceu, por exemplo, no período da Ditadura no Brasil. Reifschneider também aponta raridade para obras repudiadas pelos autores, pois alguns chegaram a recolher e destruir seus próprios livros, por não os considerar à altura de seus escritos ou por qualquer outro motivo.

Outro atributo qualificador de Obras Raras seria a encadernação de luxo, pois vários bibliófilos mandavam reencadernar seus livros com materiais nobres, como couro, metais e, por vezes, pedras preciosas; obviamente essas obras já tinham um valor cultural, histórico ou mercadológico que justificasse o gasto com tais artifícios. "As encadernações possuem seus estilos e grandes encadernadores foram e são reconhecidos através dos séculos" (Biblioteca Nacional, [2000], p.5). 
Aspectos gráficos também podem tornar um livro raro, como o caso de um erro de impressão que transforma o texto em algo caricato ou proibido.

Pinheiro (2009) resume bem a ideia do que deve ser levado em consideração ao identificar uma Obra Rara: importante observar o "limite histórico", pois o livro assume um papel novo a cada século; e o "aspecto bibliológico" que traz uma leitura do livro como objeto, com características além da informação textual, considerando-o em vários casos como obra de arte. O "valor cultural" seria aquele pelo qual o livro traz os pensamentos de uma época, enquanto a "pesquisa bibliográfica" pode revelar a escassez de um título e situá-lo dentro do contexto em que foi produzido, trazendo dados que, muitas vezes, não são possíveis de identificar no próprio exemplar, como tiragem, impressor, importância do ilustrador, do autor, entre outros aspectos. As"características do exemplar" são aquelas que não se encontram em outros exemplares da mesma edição e tiragem.

\section{Segurança contra roubo de livros raros e a Ciência da Informação}

As características que podem tornar um livro raro vão além da importância de seu conteúdo textual impresso. Uma Obra Rara carrega em si sua trajetória histórica e, também, a trajetória histórica do espaço/tempo em que foi confeccionada, pois aqueles que estavam envolvidos na sua produção - do autor ao encadernador -, aplicaram a esta obra o conhecimento adquirido por muito tempo para exercer seu ofício. Obras Raras transmitem também toda a inovação que os envolvidos na produção desses livros podem ter dado às técnicas empregadas para sua confecção.

Gauz (1994) registra a extensão da problemática da segurança em coleções de Obras Raras ao mostrar vários casos nos quais bibliotecas são invadidas e têm seus livros raros roubados, como, por exemplo, o roubo na Stanford University, em 1975. A autora ainda mostra que, em alguns casos, a ação de roubo ou furto foi facilitada por funcionário da instituição, como no caso de uma biblioteca no Rio de Janeiro (nome não citado pela autora) em 1987. Essas notícias ainda seriam acompanhadas de casos posteriores, como o do Instituto de Botânica, em
São Paulo, ocorrido em fevereiro de 2012. Este panorama mostra que a segurança de livros raros deve ser preocupação constante das instituições guardiãs deste tipo de acervo, justificando os estudos na área.

Em um livro raro a informação não está apenas presente nas palavras impressas, mas nas ilustrações, no estilo de encadernação, no papel, nos tipos gráficos, nas marcas de propriedade, entre outros aspectos que o tornam único, como exemplar, ou que permitem identificá-lo como pertencente a uma edição e/ou tiragem.

Por meio do estudo das características de produção de um livro é possível determinar o local e época onde ele foi impresso, além das ideias vigentes ou transcendentes naquele período. A Obra Rara carrega consigo o que Halbwachs (2006) chama de memória individual, pois traz a memória daqueles que a criaram, nela colocando suas inspirações e desejos, transmitindo através dos séculos, de alguma forma, os interesses pessoais de seus produtores. Demonstra, também, a memória coletiva que Halbwachs (2006) descreve, pois carrega a influência de uma sociedade, dos costumes e tradições aos quais autor, editor, impressor, ilustrador, encadernador e todos aqueles que fizeram parte da construção da obra estavam submetidos.

'Todas as características mencionadas ajudam a situar o livro, pela informação visual, dentro do que Halbwachs (2006) chama (sic.) memória coletiva e individual, pois é possível observar a identidade de uma nação nos estilos de produção do livro (encadernações, tipografia, entre outros), demonstrando características políticas, sociais, culturais e artísticas de um povo ou ainda relacionar à memória individual daqueles que o produziram, através das características que relacionam o objeto ao modo de pensar de uma pessoa, que está relacionada a vários grupos, legitimando esse pensamento individual dentro de uma memória coletiva, isso por meio dos Ex libris, impressores, tipógrafos, encadernadores e artistas do livro, que contribuíram individualmente criando e aperfeiçoando técnicas tipográficas, que refletiam os costumes e pensamentos do espaço/tempo que estavam vivenciando, repassando essas percepções às gerações futuras' (Greenhalgh; Manini, 2011, p.3).

Nesse contexto, o livro raro assume as características de documento, como mostrado por Ortega e Lara (2010) ao dizerem que "No momento em que se busca 
informação em um objeto, cuja função original é prática ou estética, 'se faz um documento'". A Obra Rara transcende a ideia de suporte da informação, pois ela toda é informação enquanto objeto histórico e patrimonial.

Como visto anteriormente, a Cl desenvolveu-se a partir da recuperação da informação. Portanto, a informação consolidada em determinado objeto ou coisa como Buckland (1991) demonstra só é passível de recuperação em sua totalidade se recuperado o objeto. 0 roubo ou furto de uma Obra Rara presente em uma biblioteca, onde está tratada e organizada para sua recuperação e acesso público, restringiria o acesso à informação presente neste livro ao domínio de seus raptores.

A representação da informação presente em uma Obra Rara pode ser usada como ferramenta de segurança. A análise bibliológica que visa a descrever todas as características intrínsecas e extrínsecas à produção de um livro raro permite individualizá-lo, servindo como uma representação do objeto que permite identificá-lo em caso de roubo e, também, como método de recuperação da informação presente neste objeto (Rodrigues et al., 2007). O mesmo ocorre com a fotobibliografia, ou didascálica - como também é chamada -, que visa a copiar a folha de rosto do livro, com a adição de duas barras indicando a quebra de linha, de modo que esta representação da informação contida na folha de rosto de uma Obra Rara permite um primeiro controle de obras ainda não catalogadas (Pinheiro, 2007). Portanto, além de tornar a obra passível de recuperação, a didascálica serve como agente de segurança, ao ser um documento da existência daquela obra na instituição.

A segurança contra roubo ou furto de Obras Raras está inserida no contexto da Cl principalmente no seu paradigma físico, no qual o livro raro é representante da definição de informação-como-coisa, e as técnicas de segurança tentam permitir que se continue a recu-

\section{Referências}

BIBLIOTECA NACIONAL (Brasil). Plano Nacional de Recuperação de Obras Raras. Critérios de raridade: empregados para a qualificação de obras raras. Rio de Janeiro: FBN, [2000]. Disponível em: <http://www.bn.br/planor/documentos.html>. Acesso em: 22 abr. 2013.

BORKO, H. Information science: what is it? American Documentation, v.19, n.1, p.3-5, 1968. peração desta informação. No entanto, o livro raro também pode se enquadrar na definição de informação-como-processo, já que é parte de um processo comunicacional, assim como no contexto da informação-como-conhecimento, pois pode preencher as lacunas de conhecimento de um indivíduo e, com isso, "diminuir suas incertezas", citando a expressão de Shannon e Weaver (1949).

\section{Conclusão}

Diante das múltiplas definições de $\mathrm{Cl}$ e de informação, a segurança contra roubo e furto do livro raro, que é entendido não só como suporte de informação, mas, também, como objeto informacional, ou informação-como-coisa, enquadra-se principalmente no paradigma físico da $\mathrm{Cl}$, pois o roubo de uma Obra Rara impede que esta esteja disponível para consulta detalhada de suas características físicas, como pigmentação de tintas, filigranas, textura dos materiais usados na confecção da encadernação ou do papel, entre outras, que não podem ser recuperadas por meio de cópias digitais da obra, acarretando em perda de informação.

A análise bibliológica torna a representação da informação uma ferramenta de segurança, já que a descrição das características de produção - ou das características adquiridas com o tempo-, do objeto ajuda a individualizá-lo e permite sua identificação em caso de roubo.

Contudo, a noção de livro raro como documento permite que este seja objeto de estudo dos paradigmas cognitivo e social, quando considerado como informação-como-processo e informação-como-conhecimento; ou seja, quando o livro raro se torna parte das necessidades de informação dos usuários motivados por desejo próprio ou pelas relações sociais nas quais está inserido, que buscam a informação presente no "objeto" Obra Rara.
BUCKLAND, M.K. Information as thing. Journal of the American Society for Information Science, v.42, n.5, p.351-360, 1991.

CAPURRO, R. Epistemologia e ciência da informação. In: ENCONTRO NACIONAL DE PESQUISA EM CIÊNCIA DA INFORMAÇÃO, 5., 2003, Belo Horizonte. Anais... Belo Horizonte: Enancib, 2003. Disponível em: <http://www.capurro.de/ enancib_p.htm>. Acesso em: 18 jun. 2012 
CAPURRO, R.; HJØRLAND, B. O conceito de informação. Perspectivas em Ciência da Informação, v.12, n.1, p.148-207, 2007. Disponível em: <http://portaldeperiodicos.eci.ufmg.br/ index.php/pci/article/view/54>. Acesso em: 18 jun. 2012.

GAUZ, V. (Org.). Segurança em acervos raros. Rio de Janeiro: Fundação Biblioteca Nacional, 1994.

GREENHALGH, R.D.; MANINI, M.P. O livro como objeto de arte. In: ENCONTRO NACIONAL DE PESQUISA EM CIÊNCIA DA INFORMAÇÃO, 12., 2011, Brasília. Anais... Brasília: UnB, 2011. 1 CD-ROM.

HALBWACHS, M. A memória coletiva. São Paulo: Centauro, 2006.

MENESES, R.V.A.; SILVA, L.A.A. A coleção de obras raras da Biblioteca Ministro Oscar Saraiva do Superior Tribunal de Justiça. BDJur, 22 jun. 2004. Disponível em: <http://bdjur. stj.gov.br/xmlui/bitstream/handle/2011/25139/Cole\%C 3\%A7\%C3\%A30_obras_raras_biblioteca.pdf?sequence $=3>$. Acesso em: 18 jun. 2012.

MORAES, R.B. O bibliófilo aprendiz. 4.ed. Brasília: Briquet de Lemos, 2005.

ORTEGA, C.D.; LARA, M.L.G. A noção de documento: de Otlet aos dias de hoje. DataGramaZero: Revista de Ciência da Informação, v.11, n.2, 2010. Disponível em: <http://www. dgz.org.br/abr10/F_I_art.htm>. Acesso em: 28 jun. 2012.

PINHEIRO, A.V. Metodologia para inventário de acervo antigo. Anais da Biblioteca Nacional, v.123, p.9-32, 2007. Disponível em: <http://www.bn.br/planor/documentos/anais_123_ 2003.pdf>. Acesso em: 2 dez. 2011.

PINHEIRO, A.V. Livro raro: antecedentes, propósitos e definições. In: SILVA, H.C.; BARROS, M.H.T.C. (Org.). Ciência da informação: múltiplos diálogos. Marília: Cultura Acadêmica, 2009. p.31-44. Disponível em: <http://www.marilia.unesp.br/
Home/Publicacoes/helen_e\%20book.pdf>. Acesso em: 18 jun. 2012.

REIFSCHNEIDER, O.D.B. A importância do acesso às obras raras. Revista lbero-Americana de Ciência da Informação, v.1, n.1, 2008. Disponível em: <http://164.41.105.3/portalnesp/ojs.1.1/ index.php/rici/article/viewFile/526/541 >. Acesso em: 18 jun. 2012.

RODRIGUES, A.H.; CALHEIROS, M.F.; COSTA, P.S. Análise bibliológica de livros raros: a preservação ao "pé da letra". Anais da Biblioteca Nacional, v.123, p.33-48, 2007. Disponível em: <http://www.bn.br/planor/documentos/anais_123_ 2003.pdf>. Acesso em: 2 dez. 2011.

RODRIGUES, M.C. Como definir e identificar obras raras? Critérios adotados pela Biblioteca Central da Universidade de Caxias do Sul. Ciência da Informação, v.35, n.1, p.115-121, 2006. Disponível em: <http://revista.ibict.br/index.php/ciinf/ article/viewFile/725/608>. Acesso em: 18 jun. 2012.

SANT'ANA, R.B. Critérios para a definição de obras raras. Revista Online Biblioteca Prof. Joel Martins, v.2, n.3, p.1-18, 2001. Disponível em: <http://www.fe.unicamp.br/revista/index. php/etd /article/view/1886/1727>. Acesso em: 18 jun. 2012.

SARACEVIC, T. Ciência da informação: origem, evolução e relações. Perspectivas em Ciência da Informação, v.1, n.1, p.4-62, 1996

SHANNON, C.E.; WEAVER, W. The mathematical theory of communication. Urbana, IL: University of Illinois Press, 1949.

UNIVERSIDADE FEDERAL DO RIO DE JANEIRO. Centro de Filosofia e Ciências Humanas. Obra rara. Rio de Janeiro: UFRJ, [2012]. Disponível em: <http://www.cfch.ufrj.br/index.php/ obras-raras>. Acesso em: 22 abr. 2012.

WERSIG, G.; NEVELING, U. The phenomena of interest to information science. Information Scientist, v.9, n.4, p.127-140, 1975. 

